\title{
Prevalence of Aggressive Behavior among Children Co-Detained with Imprisoned Mothers in a Selected Prison of North India
}

\author{
Shilpi Sarkar ${ }^{1}$ and Sandhya Gupta ${ }^{2 *}$ \\ ${ }^{1}$ Faculty-Child Health Nursing, Rufaida College of Nursing, Jamia Handard University, New Delhi \\ ${ }^{2}$ Faculty-Mental Health Nursing, College of Nursing, AIIMS, New Delhi
}

Received:March 17, 2017; Accepted: September 26, 2017; Published:November 26, 2017

*Corresponding author: Sandhya Gupta, Faculty-Mental Health Nursing, College of Nursing, AIIMS, New Delhi, E-mail:drsandhyag407@gmail.com

\begin{abstract}
Background: Prison environment cannot be same as that of home environment. A home is comprised by family members and safety umbrella of elements of basic needs essential for child growth and development. In the prison, children co-detained with imprisoned mother are surrounded by other imprisoned women and various restricted environmental factors. Environment has major influence to mould the innate tendency of aggressive behavior in the children. The objective of this study was to identify the prevalence and severity of aggressive behavior among children co-detained with imprisoned mothers.
\end{abstract}

Methods: The data was collected from the imprisoned mothers of co-detained children by direct interview technique. A structured interview schedule was used for collecting information related to child's aggressive behavior. A total of sixteen co-detained children in the age group of three to five years were included in the study.

Results: The aggressive behavior was found to be present in 13(16) co-detained children with the prevalence of $81 \%$. As far as severity of aggressive behavior is concerned, $19 \%$ of co-detained children had mild or no aggressive behavior, $31 \%$ had moderate aggressive behavior and $50 \%$ had severe aggressive behavior.

Conclusion: More than three fourth of co-detained children in the age group of three to five years were found to have moderate to severe aggressive behavior warranting the need from prison authority to develop appropriate strategies to control child exposure to violent environmental factors (real or virtual).

Keywords: Child Aggression; Violence; Young Children; Imprisoned Mother; Co-detained Children;

\section{Introduction}

Aggressive behavior is an intentional behavior that threatens or causes physical or emotional harm to self or others. It can range from verbal abuse to the destruction of a victim's personal property [1]. According to Baron and Richardson, "Aggression" is defined as any behavior intended to harm another person who does not want to be harmed [2]. According to Loeber R, Violence is aggression that has extreme harm as its goal [e.g., death] [3]. Occasional outbursts of aggression are common and even normal but becomes a problem if frequently occurs. Children with different age groups have different ways of expressing aggression. Aggressive symptoms may change with developmental competence in motor and cognitive domains. Violent behavior in children and adolescents can include a wide range of behaviors: explosive temper tantrums, physical aggression, fighting, threats or attempts to hurt others [including homicidal thoughts], use of weapons, cruelty toward animals, fire setting, intentional destruction of property and vandalism [4]. According to Joy D, childhood exposure to violence is associated with a variety of aggressive and maladaptive behaviors that can disrupt children's school adaptation and academic competence [5]. Violence exposure can lead to disturbances in cognitive functioning, emotional difficulties such as depression, anxiety, behavior and peer problems, self injury and injury to others, increased physical punishment by parents, decreased peer interactions, expulsion from child care and school settings and in the long term, they are more likely to be diagnosed with a mental health problem later in life [1].

Childhood aggression was reported to be linked to the maternal criminal history [6]. The prison barrack is most often characterized by overcrowding and excessive noise level. Codetained child is directly influenced by other prison inmate mothers and their behavioral characteristics that often fight and abuse verbally and physically. The present article identifies the occurrence and severity of aggressive behavior in the prison environment among children co-detained with imprisoned mothers. 


\section{Causes of Aggression in Children}

Man is the product of genetics and environment. Nature and nurture are partners in the development of people interaction with the environment. Human behavior is shaped by our genetic make up and environmental influences [1]. Some physical factors like extreme heat, overcrowding, loud noises, and unpleasant odors has shown to increase aggression $[7,8]$.

Genetics factor include an "aggressive predisposition", "something inbuilt" in a child's "genes" or "mental make-up". No two children or families are alike indicating the genetics factor as the reason for behavioral differences. Temperament is that aspect of personality that seems to be controlled by genetics. There are basically three types of temperament- easy or flexible [ 60 percent of children], fearful and sensitive [25 percent of children] and feisty or difficult [15 percent of children] [7]. Infants with difficult temperaments are more likely found to be aggressive and have behavioral difficulties in later childhood [9]. Olson et al revealed that preschoolers prenatally exposed to alcohol were found to be hyperactive, have frequent temper tantrums and have difficulties with transitions [10].

Environmental influences or "nurture" include experiences of the child to real-life and the virtual world. Children tend to mimic or copy whatever they observe in real world or virtual world [television or video games]. Berkowitz L found that children in their various developmental stages are most vulnerable to be influenced by aggressive environment [Real or virtual] than the adults as the adults already developed their own sets of morals and values and seeing aggression wouldn't affect them so much [8]. There are two major elements of child real environment that includes home and second one is society. The potential components of environment that could expose the children to aggressive behavior are shown in Figure 1. How people behave is silently observed by the young children and later on experimented in real life situations. According to Mitrofan et al, the environmental influences can add to child's genetic predispositions, or pre-existing behavioural problems. Reallife aggression can be verbal [people shouting or abusing each other] or physical [fighting]. When people try to solve problems with physical violence, children mistakenly learn that this is an appropriate behavior. The real life aggression has stronger behavioural effects on children [11].

\section{Violence in the virtual life situations}

The widespread exposures to violent virtual world or entertainment media contribute to the high level of violence and aggression in modern societies [12]. Children, who cannot distinguish between reality and fiction, often "imitate" their favorite virtual "hero". So if they pick up violent stuff, it's more likely they will grow up to be like that". Just as educational videogames is used in schools, according to Sherry J, violent videogames can teach aggression and increases aggressive behavior in children [13] and according to Gentile DA it develops appetite to see more violent entertainment and they become more aggressive and violent [14].

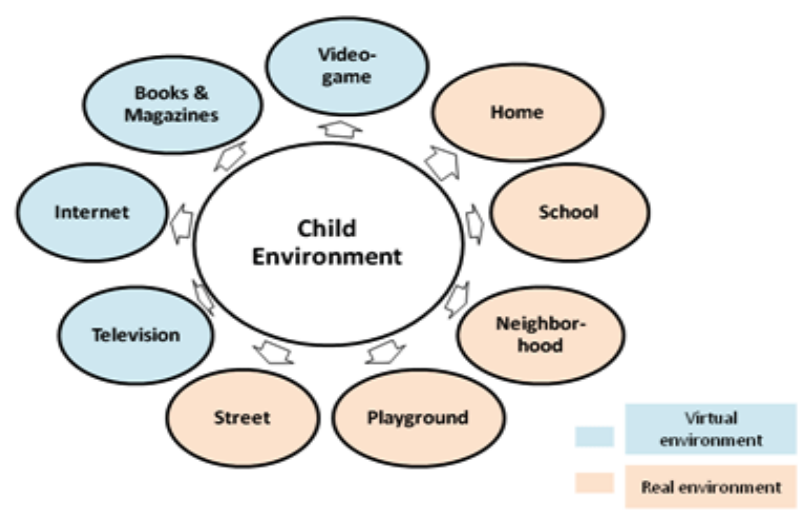

Figure 1: Component of Child Environment

\section{Methodology}

A quantitative study, cross- sectional design, the data of present study was collected from one Central prison meant for women complex of Delhi. The sample of present study comprised of co-detained children, their imprisoned mothers and prison staff working in prison crèche. Each co-detained child with imprisoned mother was considered as one pair was enrolled by total enumeration technique, three prison staff members working in the prison crèche, sixteen co-detained children in the age group of three years to five years and their imprisoned mothers were enrolled in the study. Tools used: According to Egger and Emde, problematic behaviors at the young age are typically grouped into clusters of behaviors or syndromes [e.g., hitting, biting] [16]. Therefore a self structured rating scale was developed to assess aggressive behavior among children and that included five sub categories of aggressive behaviors. The purpose of that scale was to examine co-detained child in the age group of 3-5 years for occurrence of aggressive behavior. The aggressive behavior studied were: temper tantrum, verbal hostility to other children [teasing, threats, taunts], physical hostility to other children [hitting, pinching, kicking, pushing, biting], hits or slaps own body parts, use of abusive language. The score interpretation was as severe aggression, moderate aggression or absent/mild aggression.

\section{Ethical considerations}

Permission was obtained from prison authority for the study. Informed written consent was $\backslash$ obtained from imprisoned mothers for their participation and participation of their children in the study. Verbal assent was obtained from the co-detained children to win their cooperation in the study.

\section{Delimitation}

Only those co-detained children who were attending crèche at the time of data collection were enrolled in the study.

\section{Procedure of data collection}

Permission was obtained from prison authority for the data collection for the study. After initial screening, all co-detained 
children in the age group of three to five years were selected for the study. Information about the study purpose and method was explained to the prison crèche staff and imprisoned mothers. Doubts and questions were answered. Informed written consent was obtained from the mothers and prison crèche staff for their participation and participation of their co-detained children. Verbal assent was obtained from children to win their cooperative participation. Prison staff members of the crèche were interviewed all together to rate each individual child's behavior using the tool "Aggressive behavior inventory for children".

\section{Results}

A total of sixteen co-detained children in the age group of three to five years were included in the study. Out of sixteen codetained children, 13 [81\%, 95\% C.I: 57\% - 93\%] were found to have moderate to severe grades of aggressive behavior and only 3 [19\%, 95\% C.I: $6.5 \%$ - 43\%] were having mild aggression or no aggression (Figure. 2).

Severity of aggressive behavior scores among co-detained children is shown in (Figure 3), only nineteen percentage (95\% C.I: $6.5 \%-43 \%$,) of co-detained children were having mild or no aggressive behavior whereas, most of the co-detained children were having either moderate 31\% (95\% C.I: $14 \%$ - 55\%) or sever aggressive behavior 50\% (95\% C.I: $28 \%-72 \%$ ).

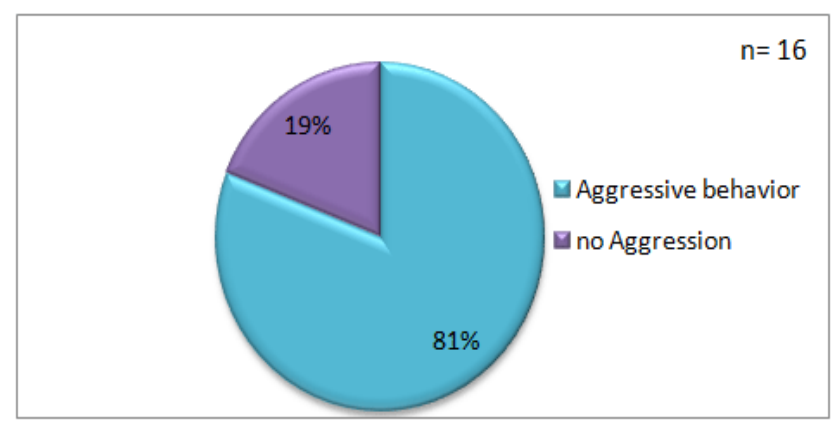

Figure 2: Prevalence of aggression in Co-detrained children

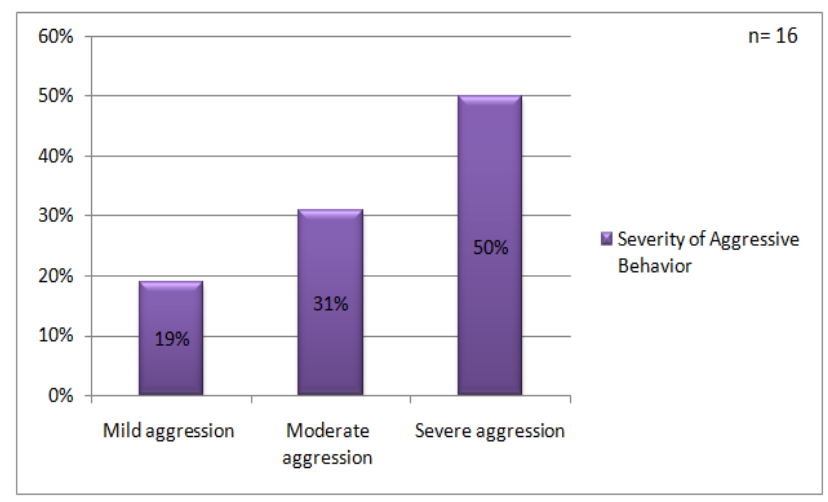

Figure 3: Severity of aggressive behavior among co-detained children
It is evident from the Table 1 that out of 16 pre-school age children, there were eight co-detained children who were having severe aggressive behavior in all aggressive behavior types that is temper tantrum, teasing/threats, hitting others, hitting self and use of abusive language.

Table 1: Distribution of co-detained children according to types of aggressive behavior

\begin{tabular}{|l|c|c|}
\hline \multicolumn{1}{|c|}{$\begin{array}{c}\text { Types of aggressive } \\
\text { behavior }\end{array}$} & $\begin{array}{c}\text { Severity of aggressive } \\
\text { behavior }\end{array}$ & Frequency (\%) \\
\hline Temper tantrum & No problem & $03(19)$ \\
& Mild problem \\
Moderate problem & - \\
Severe problem & $05(31)$ \\
Teasing, threats, & No problem & $03(50)$ \\
taunts & Mild problem & - \\
& Moderate problem & $05(31)$ \\
\hline Hitting, pinching, & Severe problem & $08(50)$ \\
kicking, pushing, & No problem & - \\
biting & Mild problem & $3(19)$ \\
& Moderate problem & $5(31)$ \\
\hline Hits or slaps own & Severe problem & $8(50)$ \\
body parts & No problem & $2(13)$ \\
& Mild problem & $1(06)$ \\
& Moderate problem & $5(31)$ \\
\hline Use of abusive & Severe problem & $8(50)$ \\
language & No problem & $03(19)$ \\
& Mild problem & - \\
\hline & Moderate problem & $05(31)$ \\
& Severe problem & $08(50)$ \\
\hline
\end{tabular}

\section{Discussion}

Aggression in young children was reported by Bor W, to be a stronger predictor of delinquency than gender (being male), poverty, family structure and maternal education. It increases a child's risk of delinquency by a factor of 4.48. [17]. In the prison, imprisoned mother is the only support system for co-detained child, there is lack of father's role and often there is dominance of aggressive behavior of other imprisoned mothers. Aggressive behavior can adversely affect the physical and psychological health of the children.

\section{Home versus prison environment}

Home includes parents, siblings and other family member. They act as role model for the children. Unlike home, in prison imprisoned mother is the only family member for the child. According to Joy D et al, behavior problems that emerge in a child following exposure to violence can be thought of as stemming from a lack of appropriate role models, difficulties with emotion regulation skills and aberrant information processing [5]. Aggression in the parental behavior, family dysfunction and parental attitude greatly influence child behavior. The presence of siblings who serve as a target for aggression is an indirect effect and increases the risk of becoming physically aggressive in the high aggression trajectory group [6]. The impact of family arguing and physical violence is long standing, with implications for deviated adult behavior and functioning in later years [18]. 


\section{Community violence versus violent behavior inside the prison}

Community violence includes exposure of the children to violence in the school, park and peer group. When children see people getting violent and getting positive benefits they get positively reinforced to practice violence in their life. Inside the prison, sometimes unhealthy behavior of imprisoned mothers (shouting, abusing, frequent fights etc) may get dominated and children might learn the characteristics of unhealthy behavior which is awarding in terms of fulfillment of needs irrespective of whether good or bad nature of behavior. It has been observed by Mitrofan $\mathrm{O}$ that when people try to solve problems with physical violence, children mistakenly learn aggressive behavior as an appropriate behavior [11].

\section{Imprisoned mothers' behavior}

Parents are the best modeling character for children. Imprisoned mother is the only support system for co-detained child. In addition to this there is lack of father's role and there is dominance of aggressive behavior of other imprisoned mothers. Usually children learn to mimic the parental behavior. According to Weiss $\mathrm{B}$, parents who frequently exercise aggression in the form of verbal or physical discomfort to manage their child's behavior were far more likely found to have aggressive children than parents who use more positive strategies [19]. Parental aggressive behavior such as scolding, threatening, yelling, and battering encourages a child to deal with their problems in the very same ways. Verbal aggression in parents, even in the absence of physical aggression was found [Vissing YM 1991] to be linked to aggression as well as delinquency and interpersonal problems among children [20]. According to Campbell, pre-school children are more likely to show overactive, noncompliant, aggressive and impulsive behavior in the context of uninvolved, rejecting or harsh parenting [21].

\section{Family Dysfunction/Disruption}

Co-detained child's situation in prsion is more or less similar to single parent family and there is evidence that single parenthood, divorce and reconstituted families, poverty, maternal depression, alcohol and substance abuse, all have been positively related to children's aggressive behaviors. Children from homes where domestic violence is occurring are reported (Mathias JL, Stenberg and Mertin M) to more likely exhibit aggressive behavior [22,24].

\section{Anti-social parental attitude}

Imprisoned mother might have difficulty to regulate the behavior of co-detained children in the common living room. The link between parental antisocial attitudes and violent behavior of children has been reported by Hawkins et al [25] Parents who don't discourage aggressive behavior in children are reported by Gottfredson as indirectly giving permission to be aggressive by their own parents [26].

\section{Television watching by the co-detained children}

Children stay with their imprisoned mothers all together in a common barrack. There is only one television for the entertainment of all inmates of the barrack. Television programs are reported (Fried et al., 2000; Gupta et al., 2001) to provoke aggressive fantasies and aggressive behavior among children and preschoolers seem to be most susceptible $[27,28]$.

Inside the prison mother is the only support system for the child. It has been reported by Hagen KA et al that children with low levels of social support have more externalizing and internalizing problems [29]. It has been repeatedly reported in previous studies by Briggs-Gowan MJ et al and Essex MJ et al that young children with recurrent and comorbid aggressive behavior have the most impairment, greater problem stability and higher subsequent utilization of mental health services [30, 31]. Therefore, co-detained children experiencing aggressive behavior demand special provisions and practices on the part of prison authority and government. Some of the practices may include child counseling services, parenting educational programs for mothers, training of the crèche teachers to manage aggressive behavior in the initial stages.

\section{Conclusion}

Children co-detained with imprisoned mothers are inevitably exposed to aggressive environmental influence created by other imprisoned women. More than three fourth of co-detained children in the age group of three to five years were found to have moderate to severe aggressive behavior warranting the need from prison authority to develop appropriate strategies to control child exposure to violent environmental factors (real or virtual).

If violence exposure can be terminated, the plasticity in children's developmental processes might promote recovery of their behavior. Therefore prison authority must adopt certain rules to prevent environmental exposure of violence (virtual or real) to the co-detained children.

\section{Implication of the study}

Strict prison policy is required against the use of abusive language and prevention of frequent fights among prisoners. The prison should develop strategies to avoid exposure of children to violent TV programs. The prison should plan child counseling services for the aggressive children. Parenting classes needs to be organized for imprisoned mothers. Training of the teachers in crèche to manage aggressive behavior of the child in the early stages.

\section{References}

1. Sarah Fried. Biological Influences on Human Behavior: Genetics \& Environment.

2. Baron RA, Richardson DR. Human aggression (2nd ed.). New York: Plenum Press. 1994;

3. Loeber R, Green SM, Lahey BB, Kalb L. Physical fighting in childhood as a risk factor for later mental health problems. J Am Acad Child Adolesc Psychiatry. 2000;39(4):421-428.

4. AACAP. Understanding Violent Behavior in Children and Adolescents: Facts for Families. American Academy of Child and Adolescent Psychiatry. 2011; 
5. Osofsky JD, Osofsk HJ. Children's Exposure to Violence - Community Violence, Domestic Violence - General effects. Envision summer programs.

6. Tremblay RE, Daniel S, Nagin J, Seguin R, Zoccolilillo M, Zelazo PD, Boivin, et al. Physical aggression during early childhood: Trajectories and predictors. Pediatrics. 2004;114:e43-e50.

7. Child Development Specialist, Department of Family and Consumer Sciences. Childhood Aggression: Where does it come from? How can it be managed? North Carolina Cooperative Extension Service.

8. Berkowitz L. On the formation and regulation of anger and aggression: a cognitive neoassociationistic analysis. Am Psychol. 1990;45(4):494503

9. Kingston L, Prior M. The development of patterns of stable, transient and school age aggressive behavior in young children. J Am Acad Child Adolesc Psychiatry. 1995;34(3):348-358.

10. Olson HC, Burgess DM, Streissguth A. Fetal alcohol syndrome (FAS) and fetal alcohol effects (FAE): A life span view with implications for early intervention. Zero to Three. 1992;13:24-29.

11. Mitrofan O, Paul M, Weich S, Spencer N. Aggression in children with behavioural/emotional difficulties: seeing aggression on television and video games. BMC Psychiatry. 2014;14:287.

12. Bushman BJ, Huesmann LR. Effects of televised violence on aggression. In Handbook of Children and the Media, ed.DSinger, J Singer. 223-254.

13. Sherry J. The effects of violent video games on aggression: A metaanalysis. Hum Commun Res. 2001;27:409-431.

14. Gentile DA, Lynch PJ, Linder JR, Walsh DA. The effects of violent video game habits on adolescent hostility, aggressive behaviors, and school performance. Journal of Adolescence. 27(1),5-22.

15. Bandura, A. (1977). Social Learning Theory. Englewood Cliffs, NJ: Prentice Hall.

16. Egger HL, Emde RN. Developmentally sensitive diagnostic criteria for mental health disorders in early childhood: The diagnostic and statistical manual of mental disorders-IV, the research diagnostic criteria-preschool age, and the diagnostic classification of mental health and developmental disorders of infancy and early childhoodrevised. Am Psychol. 2011;66(2):95-106.

17. Bor W, Najman JM, O'Callaghan M, Williams GM, Anstey K. Aggression and the development of delinquent behaviour in children', Australian Institute of Criminology: Trends \& Issues in Crime and Criminal Justice. Australian Institute of Criminology. 2001;

18. Paradis AD, Reinherz HZ, Giaconia RM, Beardslee WR, Ward K, Fitzmaurice GM. (2009). Long-term impact of family arguments and physical violence on adult functioning at age 30 years: Findings from the Simmons Longitudinal Study. J Am Acad Child Adolesc Psychiatry. 2009;48(3):290-298.
19. Weiss B, Dodge KA, Bates JE, Pettit GS. Some consequences of early harsh discipline: child aggression and a maladaptive social information processing style. Child Dev. 1992;63(6):1321-1335.

20.Vissing YM, Straus MA, Geller RJ, Harrop JW. Verbal aggression by parents and psychosocial problems of children. Child Abuse Negl. 1991;15(3):223-238.

21. Campbell SB. Behaviour problems in preschool children: A review of recent research. J Child Psychol Psychiatry. 1995;36(1):115-119.

22. Mathias JL, Mertin P, Murray A. The psychological functioning of children from backgrounds of domestic violence. Australian Psychologist. 1995;30(1):47-56.

23. Sternberg KJ, Lamb ME, Greenbaum C, Cichetti C, Dawud S, Cortes R, et al. Effects of domestic violence on children's behaviour problems and depression. Developmental psychology. 1993;29(1):44-52.

24. Mertin M, Mathias J. Children of Domestic violence: Effects on Behavioural Emotional and Psychological functioning. South Australian Department of Family and Community Services, Adelaide.

25. Hawkins JD, Herrenkohl TL, Farrington DP, Brewer D, Catalano RF, Harachi TW. A review of predictors of youth violence. In: Loeber $\mathrm{R}$, Farrington DP, editors. Serious and violent juvenile offenders: Risk factors and successful interventions. Thousand Oaks, CA: Sage. 1998;106-114

26. Gottfredson MR, Hirschi T. Ageneral theory of crime, Stanford, CA: Stanford University Press. 1990;

27. Fried CS, Reppucci ND, Woolard JL. Youth violence. In: Rappaport J, Siedman E, editors. Handbook of community psychology. New York: Plenum; 2000

28. Gupta VB, Nwosa NM, Nadel TA, Inamdar S. Externalizing behaviors and television viewing in children of low-income minority parents. Clin Pediatr. 2001;40(6):337-341.

29. Hagen KA, Myers BJ. The effect of secrecy and social support on behavioral problems in children of incarcerated women. Journal of Child and Family Studies. 2003;12(2):229-242.

30. Briggs-Gowan MJ, Carter AS, Bosson-Heenan J, Guyer AE, Horwitz SM. Are infant-toddler social-emotional and behavioral problems transient? J Am Acad Child Adolesc Psychiatry. 2006;45(7):849-858. doi:10.1097/01.chi.0000220849.48650.59

31.Essex MJ, Kraemer HC, Slattery MJ, Burk LR, Boyce WT, Woodward HR, et al. Screening for childhood mental health problems: Outcomes and early identification. J Child Psychol Psychiatry. 2009;50:562-570. doi:10.1111/j.1469-7610.2008.02015.x 